\title{
Manager And Business Student Work Goals: Implications And Recommendations For Educators
}

Clinton H. Richards, University of Nevada, Las Vegas, USA

William J. Corney, University of Nevada, Las Vegas, USA

\begin{abstract}
The correspondence between work goals, work requirements, and available organizational rewards is a primary determinant of job satisfaction and motivation and is also likely to impact job performance. Research suggests managers' but not business students' work goal priorities are well matched with the work requirements and available rewards of modern business organizations. Educational implications are discussed and recommendations are made to increase students' understanding of the importance and impact of work goals in modern organizations and to facilitate their adjustment to the reward conditions and work requirements that they are likely to face in these organizations. The recommended work goal and adjustment module, which is integrated into the topic of motivation, is also expected to increase student understanding and interest in the motivation material by encouraging students to apply it to work adjustment and by helping them more personally relate to the motivation principles applied.
\end{abstract}

Keywords: work goals; business education; work adjustment

\section{INTRODUCTION}

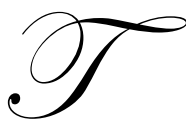

he fit between work competencies and requirements and between reward preferences and their availability are considered critical for satisfaction, motivation, and performance (Dawis and Lofquist, 1984; Hershenson, 1996; Rich, et al., 2010). Business educators have focused on the matching of student competencies with the work requirements of modern organizations, but the fit between desired and available rewards has the greater impact on satisfaction and motivation (Locke, 1976; Roberson, 1990; Edwards, 1991; Maier and Brunstein, 2001) and the pursuit of some of these rewards is likely to affect work competencies as well. Reward preferences are shaped by individual needs and also by the environment through education, socialization, and direct experience (Weiner and Klein, 1978; Dawis and Lofquist, 1984; Hershenson, 1996; Peterson and Ruiz-Quintanilla, 2003). Reward availability is also shaped by a number of environmental factors including organization and job design.

The landmark Meaning of Work project (MOW International Research Team, 1987) examined and compared the reward preferences and work attitudes of managers, first-line supervisors, and non-supervisory employees in seven industrialized countries. Perhaps the "most empirically rigorous research ever undertaken to understand, both within and between countries, the meanings people attach to their work roles" (Brief, 1991, p. 176), the importance and structure of it's core concepts continue to be supported (Harpaz and Xuanning, 2002; Peterson and Ruiz-Quintanilla, 2003) and used in cross-cultural studies (e.g., see Pearson and Chatterjee, 1999; Corney and Richards, 2001, 2005; Chan and Pearson, 2002; Ardichvili, 2005; Ejere, 2010). The project's research team chose 11 work goals to examine after an extensive international review of studies on work values and job satisfaction. The work goals are shown in Table 1 with their rankings by U.S. managers in the Meaning of Work study (MOW International Research Team, 1987; Harpaz, 1990). They include learning and expressive work goals related to intrinsic rewards as well as work goals requiring extrinsic rewards for their satisfaction. Current trends in job and organization design impact the availability of rewards associated with a number of these goals and thus can be expected to differentially affect the satisfaction and motivation of 
employees with different work goal priorities. Some of the work goals are also likely to affect the development of work competencies.

This paper briefly reviews work adjustment concepts and theory as well as some current job and organization design trends affecting the satisfaction and value of the MOW work goals; describes and compares the work goal priorities of business students and managers found in previous research; and discusses implications for work adjustment and for the education of business students. The paper concludes with a set of recommendations designed to improve the match between student work goals and the likely organizational rewards and job requirements they will face in their careers. The recommendations focus on 1) increasing students' understanding of the importance and impact of work goals in modern organizations and 2) encouraging students to examine and compare their own work goals and those of managers in light of organizational trends and conditions affecting work goal satisfaction and importance.

Table 1: MOW Work Goals As Ranked By U.S. Managers

\begin{tabular}{|c|l|}
\hline Rank & Work Goal \\
\hline 1 & Interesting work (work that you really like) \\
\hline 2 & A lot of autonomy (you decide how to do your work) \\
\hline 3 & A lot of variety \\
\hline 4 & A good match between job requirements and your abilities and experience \\
\hline 5 & A lot of opportunity to learn new things \\
\hline 6 & Good pay \\
\hline 7 & Good interpersonal relations (supervisors, co-workers) \\
\hline 8 & Good job security \\
\hline 9 & Convenient work hours \\
\hline 10 & Good opportunity for upgrading or promotion \\
\hline 11 & Good physical working conditions (such as light, temperature, cleanliness, low noise level) \\
\hline
\end{tabular}

\section{WORK GOAL IMPORTANCE}

The importance of a work goal affects the extent of its impact on job satisfaction (Harris et al., 2003) and depends not only on its intrinsic value but also on its instrumentality in attaining other valued rewards and outcomes. Good pay, for example, has little intrinsic but much instrumental value, while the satisfaction of a number of the other MOW work goals is likely to have significant intrinsic as well as instrumental value. Variety, autonomy, and learning opportunities are not only likely to be intrinsically rewarding but also instrumental in enhancing competencies important in achieving satisfactory performance and obtaining performance-based extrinsic and intrinsic rewards (Dodd and Ganster, 1996; Rich, et al., 2010). Interesting work and a good match between job requirements and abilities should also lead to more intrinsically rewarding work, higher motivation and performance, and greater performance-based rewards. Good interpersonal relations can also be both intrinsically satisfying and instrumental in accomplishing task goals, particularly in team structures.

The importance of a work goal also depends on the extent to which it has already been satisfied and the probability of attaining more of it. A completely satisfied work goal loses its importance, while the importance of a partially satisfied work goal may be increased or decreased by the probability of attaining more of it. Functional work goal adjustment occurs when individuals are able to reduce their emphasis on work goals that are unattainable and increase attention to work goals that are attainable and have high intrinsic and instrumental values. However, some work goals attached to important needs may continue to be emphasized even when unlikely to be satisfied. Although dysfunctional for work adjustment, Aronson (1984) notes that low expectations about the attainability of a goal can increase its perceived importance. For some, the security work goal may be an example.

The relatively high levels of satisfaction found among U.S. employees (Clark, 2005) indicate that they have generally been successful in adjusting to the availability of rewards in their organizational environments, but some are unable to adjust their goals to available rewards. Employees may also give more or less emphasis to a work goal than is appropriate because they misjudge its instrumentality or intrinsic value. Information and knowledge are keys to the accurate assessment of these values, and may come through experiential or vicarious learning. Modeling and imitation 
are two important forms of vicarious learning (Bandura, 1977) which Hershenson (1996) contends are particularly influential in shaping work goals.

\section{WORK ADJUSTMENT PROCESS}

Work adjustment is defined as the "continuous and dynamic process by which the individual seeks to achieve and maintain correspondence with the work environment" (Dawis and Lofquist, 1984, p. 55). The individual seeks to increase correspondence by responding actively in changing the environment or reactively by adjusting goals and/or competencies (Dawis and Lofquist, 1984). The correspondence between work competencies and requirements has its primary effect on performance, while the correspondence between work goals and available rewards has its primary effect on job satisfaction and motivation. Both competencies and work goals are likely to also have secondary effects on satisfaction and performance, however, because of interactions between work competencies and goals and between performance and satisfaction (Hershenson, 1996).

Lower performance or satisfaction is expected when employees inaccurately perceive or inappropriately weight the importance of work competencies or goals. Although the focus in this paper will be on work goals, we will also note when and how these work goals can increase competencies and thus their importance.

\section{JOB DESIGN AND ORGANIZATIONAL TRENDS}

Job enlargement, enrichment, and the job characteristics model provide job design approaches that are common in modern organizations and commonly described in introduction to business and principles of management textbooks. All three approaches increase task and skill variety and thus result in a heightened need for employee learning. Job enrichment and the job characteristics model also increase autonomy. The importance of a good match between the demands of a job and the skills of the job holder is increased when the job contains high variety and autonomy, while the need for coordination and supervision is reduced. This facilitates the structural change to flatter organizational hierarchies. While obvious cost advantages can ensue from the reduced hierarchy, a negative consequence for managers is the resulting reduction in job security and promotion opportunities. Current downsizing and outsourcing trends also reduce job security in the work place. Employee attitudes have also contributed to a change in the social contract between employee and employer away from reciprocal loyalty and towards rewards based on today rather than yesterday's contributions (Carroll and Buchholtz, 2009).

Applications of socio technical systems theory (Trist, 1981) and reengineering (Hammer and Champy, 1993) are also popular in business organizations although they are less often described in management textbooks. The theories incorporate variety and autonomy with team-based principles integral to the design of the part-time, temporary, and fulltime teams that are becoming increasingly pervasive in modern organizations (Stewart et. al, 1999; Bughin et. al, 2010; Klein et al., 2011).

The described job design and organizational trends clearly impact the availability of rewards and the instrumentalities associated with a number of the MOW work goals and thus affect the person-environment fit (Kulik et al., 1987). Employees with strong variety, autonomy, and learning work goals should experience greater satisfaction and motivation in work settings shaped by these job design approaches, and are likely to perform better in them. Recognition of the importance of matching abilities with expanded job requirements is similarly likely to serve employees well. Those in team-oriented work environments are also likely to find good interpersonal relations not only intrinsically satisfying but also instrumental in task accomplishment. Strong promotion and job security goals, on the other hand, do not appear conducive to job satisfaction given current downsizing and outsourcing trends and the flattening of organizational structures.

\section{MANAGER AND STUDENT WORK GOAL PRIORITIES}

The work goal priorities of managers and business students found in previous research (MOW International Research Team, 1987; Harpaz, 1990; Richards and Corney, 2008) suggest that the managers but not the students' work goals were well matched with the available rewards and job requirements of modern organizations. U.S. managers highly valued the job autonomy, variety, and learning opportunities that are increasingly available in modern 
organizations, and recognized the importance of matching job requirements with their skills and abilities (Harpaz, 1990). U.S. business students, like the managers, appreciated the importance of interesting work, but apparently didn't see a strong connection between it and job variety or autonomy. Students rated autonomy, variety, and a good job/skill match lower than any other work goals, and only upper division students rated learning opportunities highly (Richards and Corney, 2008). The low ratings given autonomy and variety by the students suggest a poor match with jobs designed under currently popular theories. The low rating both upper and lower division students gave to the importance of matching abilities to job requirements in the study is also troubling since a good match is likely to result in more intrinsically rewarding work, higher performance, and greater performance-based extrinsic rewards. At the other end of the scale, the high priority both lower and upper division students gave to promotion opportunities (ranked $1^{\text {st }}$ and $2^{\text {nd }}$, respectively, compared to $10^{\text {th }}$ by managers) portends future dissatisfaction in the students' careers unless they either adjust this goal's priority or the current trend toward the flattening of organization structures subsides or is reversed. Students surveyed also gave a higher priority to job security than managers. However, the difference between upper division students and managers was less pronounced than the difference between lower division students and managers. Upper division students ranked security $6^{\text {th }}$, lower division students ranked it $4^{\text {th }}$, and managers ranked it $8^{\text {th }}$. Downsizing, outsourcing, and the dynamic nature of business needs all play a role in reducing job security and focusing rewards on today rather than yesterday's contributions (Carroll and Buchholtz, 2009). In such an environment, the keys to work security appear to be competence and learning rather than tenure and loyalty.

Although the student work goal priorities displayed in the Richards and Corney study were generally not well matched with the organizational environments that business school graduates are likely to face, some functional work goal changes did appear to occur as students progressed through the business curriculum. Upper division students placed greater priority on learning opportunities than their lower division counterparts. They also valued good interpersonal relations more highly, a change which appears particularly functional for adjustment to the team-oriented organizational structures of many of today's modern organizations.

\section{EDUCATIONAL IMPLICATIONS}

The key tenet of work adjustment theory is that satisfactory adjustment requires a correspondence between a worker's competencies and job requirements and between available rewards and the worker's psychological needs or goals. Business education has naturally focused on the development of student competencies. Although the curriculum typically includes some coverage of organizational and job design trends, little attention is given to their impact on work goals and adjustment. This may contribute to the relatively poor match found between student work goal priorities and the rewards and requirements of modern organizations. We believe that providing more information about the work goals likely to be most functional for managerial performance and satisfaction will encourage self-examination and work goal adjustment among students where appropriate. We also believe providing information on the correspondence between practicing managers' work goals and the demands and rewards of their work will facilitate this work goal adjustment. Work adjustment, vocational counseling, and social learning theories (Bandura, 1977; Dawis and Lofquist, 1984; Hershenson, 1996) all suggest the efficacy of examining personal work goals and comparing them to those of appropriate models (e.g., managers). Dawis and Lofquist's (1984) contention that work adjustment constructs are particularly useful in the study of motivation suggests that an appropriate location for a work-adjustment learning module is within the motivation section of the introduction to business and/or principles of management course common in business curricula.

\section{RECOMMENDATIONS}

Inserting a work adjustment learning module after the topic of motivation is an excellent way of reviewing key motivation concepts, applying them to the work adjustment process and outcomes, and encouraging self-examination of work goals and functional adjustment of priorities. The work adjustment learning module we recommend includes eight components or sections. We recommend all, but since that may take the better part of a class period, we understand that some educators may want to eliminate some of the components in the interests of time. However, we believe even a truncated module can improve student understanding of the importance of work goals and their impact on satisfaction, motivation, and performance. The eight components of the full module include 1) a description of key work goal adjustment principles and the work goal priorities of practicing managers identified in previous research; 2) discussion of the extrinsic and intrinsic rewards likely to be associated with the top work goal priorities of managers, and their likely 
impacts on performance; 3) discussion of the implications of managers' top work goal priorities under expectancy and equity theories; 4) discussion of the implications of Maslow and Herzberg's motivation theories for work goal priorities and their effects; 5) discussion of application of work goal and adjustment principles to differences in employee work goal priorities; 6) discussion of the implications of modern job design approaches and organizational trends; 7) presentation and discussion of significant differences between upper and lower division students' work goal priorities found in a previous study; and 8) student self-examination of their own work goal priorities.

\section{Description Of Key Work Goal Adjustment Principles And Managers’ Top Priorities}

The first component of the module includes the presentation of background information on the MOW work goals and the reasons for their selection along with a description of key work goal adjustment principles described in the "Work Goal Importance" and "Work Adjustment Process" sections of this paper. It concludes with the presentation of a PowerPoint slide showing the top five work goal priorities of U.S. managers in the MOW study (interesting work, autonomy, variety, a job which is a good match with abilities, and learning opportunities). We leave this slide up until we replace it during discussion of the implications of Maslow and Herzberg's theories with a slide showing the rankings of the 11 work goals by first-level supervisors, other U.S. managers, and non-supervisory personnel (see Table 2).

\section{Discussion Of The Extrinsic And Intrinsic Rewards Associated With Managers' Top Work Goal Priorities}

The possible extrinsic and intrinsic rewards associated with the managers' top five work goal priorities are discussed here. Although we are relatively successful in encouraging students to identify these rewards, perhaps because we reward participation throughout the course, students seldom make all of the points that we want brought up in this or subsequent components of the learning module. While the goal is to get students to bring up as much of it as possible, and instructor-provided feedback on student comments facilitates that, we recommend the instructor go beyond merely providing feedback when it is necessary to accomplish his or her goals. In this section of the module, we add as necessary to assure that students understand how the managers' top five work goals can be intrinsically rewarding as well as instrumental in enhancing competencies and obtaining performance-based rewards.

\section{Discussion Of The Implications Of Managers' Top Work Goal Priorities Under Expectancy And Equity Theories}

We begin this section by explaining how work goal priorities reflect the value or valence of different rewards, and then contrast equity and expectancy theory in terms of work goal satisfaction and motivation. We note that equity theory suggests high motivation whenever work goal priorities are highly satisfied while expectancy theory suggests individuals will be highly motivated only if they think greater satisfaction of their work goal priorities is contingent on that highly motivated behavior. Students are then asked if the manager's motivation and performance might increase the likelihood of attaining any of the managers' top five work goal priorities. We add to their comments as necessary to enhance students' understanding of 1) how higher motivation in many cases can contribute to managers' performance and lead to work that is more interesting and provides greater variety and autonomy, and 2) how a better job/skill match and greater learning opportunities can improve present and future performance and thus lead to higher performancebased rewards.

\section{Discussion Of The Implications Of Maslow And Herzberg's Motivation Theories For Work Goal Priorities And Their Effects}

We first note that Maslow and Herzberg propose needs which appear to impact the value or importance of satisfying the managers' top work goal priorities, and ask students to explain. Again, we add to student comments as appropriate, in this case to assure that students understand the relationships between the managers' top work goal priorities and Maslow's higher order needs, Herzberg's motivators, and the implications for managers' motivation.

We next present a PowerPoint similar to Table 2 displaying the rankings of the 11 work goals by first-level supervisors, other U.S. managers, and non-supervisory personnel; and initiate a discussion of the differences among the three groups in their rankings of job autonomy, variety, pay, and security. We ask how Maslow's theory might explain these differences (lower vs. higher order need strengths and satisfactions) and what Herzberg's theory would suggest in terms of effects on motivation and satisfaction (motivators stronger with managers while hygiene factors emphasized 
more by first line supervisors and non-supervisory employees). We also note, if students don't, that greater confidence among managers in their skills and abilities may make them feel more secure and increase their desire for greater challenge through jobs with higher autonomy and variety.

\section{Discussion Of Application Of Work Goal And Adjustment Principles To Differences In Employee Work Goal Priorities}

We begin this section by pointing out the different priorities given autonomy, variety, pay, and security by the three employee groups and asking how work goal adjustment principles might explain these differences. We then turn to the low priority all employee groups gave to promotion opportunities and ask how this might be explained. As before, we describe appropriate applications ourselves only when we are unable to elicit the desired points from students through feedback and reinforcement of their comments.

Table 2: Employee Work Goal Priorities

\begin{tabular}{|l|c|c|c|}
\hline & Managers & Supervisors & Other Employees \\
\hline Work Goals & Rank & Rank & Rank \\
\hline Interesting Work & 1 & 1 & 9 \\
\hline High Autonomy & 2 & 5 & 7 \\
\hline High Variety & 3 & 6 & 5 \\
\hline Match Abilities with Job & 4 & 8 & 4 \\
\hline Learning Opportunities & 5 & 3 & 3 \\
\hline Good Pay & 6 & 2 & 6 \\
\hline Good Interpersonal Relations & 7 & 7 & 3 \\
\hline Good Job Security & 8 & 4 & 8 \\
\hline Convenient Work Hours & 9 & 10 & 10 \\
\hline Promotion Opportunities & 10 & 9 & 11 \\
\hline Good Working Conditions & 11 & 11 & \\
\hline
\end{tabular}

\section{Discussion Of The Implications Of Modern Job Design Approaches And Organizational Trends For Work Goal Importance}

This component of the module begins with a discussion of the extent to which the different employee groups' top work goal priorities fit with jobs designed with enlargement, enrichment, and the job characteristics model. Alternative explanations for the differences, including differences in the availability of or adjustment to enlarged and enriched jobs, are discussed next along with expected effects. We also bring up contributing factors and the effects suggested by theories discussed in previous components of the module. Finally, we discuss the fit between different employee groups' priorities and organizational trends such as downsizing, decentralization, the flattening of organizational structures, and greater use of teams that were covered in previous chapters.

\section{Presentation And Discussion Of Significant Differences Between Upper And Lower Division Students' Work Goal Priorities}

Here we tell students that a previous study found upper division business students rated autonomy, variety, learning opportunities, and good interpersonal relations significantly higher than lower division business students, and ask why they think this may have occurred. We bring up, as necessary, the business curriculum's emphasis on learning, the learning that occurs in it, and the extensive use of team projects in the curriculum.

\section{Student Self-Examination Of Work Goals}

Students are asked to rank and rate the importance of the 11 work goals (on a 10 point scale) on a form similar to the one used by Richards and Corney (2008). If time permits, the work goal and adjustment module ends with a concluding discussion. In any case, students are told to keep their filled-out form for their own information. Students may also be given credit for an essay on why they rated/ranked the work goals as they did. This essay can be one option 
for students in fulfilling a written assignment requirement. Written assignments are required in all business core courses in some curricula, including the one in which we teach.

\section{CONCLUSIONS}

Research suggests that the work goal priorities of managers but not business students are compatible with current job design and organizational trends affecting the modern business organization. This suggests potential work adjustment problems in the form of lowered job satisfaction, motivation, and perhaps performance. Consistent with research and theory on work adjustment, goal adjustment, and role modeling, we believe educators can facilitate their students' work adjustment by enabling and encouraging students to examine their own work goals in comparison to those of managers and in light of current trends affecting organizational rewards, work requirements, and conditions. Recommendations are made to do this by integrating a work adjustment learning module into the motivation section of the introduction to business or principles of management course. We believe use of the module improves student understanding of the work adjustment process and the importance of various work goals, encourages functional work adjustment on their part, and increases understanding and interest in the motivation material by helping students apply and more personally relate to it.

\section{AUTHOR INFORMATION}

Clinton Richards is an Associate Professor of Management at the University of Nevada, Las Vegas. His current research focus is on the impact of education on work goals and ethical decision making. He has taught a variety of courses at the graduate and undergraduate levels, most recently in the areas of business law, society, and ethics.

E-mail: clint.richards@unlv.edu

William Corney is Professor of Management at the University of Nevada, Las Vegas. Courses taught are in the areas of operations management and international management. His research interests are in human workplace development and business operational feedback systems. E-mail: William.Corney@unlv.edu

\section{REFERENCES}

1. Ardichvili, A. 2005. The Meaning of Working and Professional Development Needs of Employees in a Post-Communist Country. International Journal of Cross Cultural Management: CCM, 5, 105-119.

2. $\quad$ Aronson, E. 1984. The Social Animal. $4^{\text {th }}$ edition. New York.

3. Bandura, A. 1977. Social Learning Theory. Englewood Cliffs, N.J.: Prentice Hall.

4. Brief, A. P. 1991. MOW Revisited: A Brief Commentary. European Work and Organizational Psychology, 1, 176-182.

5. Bughin, J., Chui, M. and Manyika, J. 2010. Clouds, Big Data, and Smart Assets: Ten Tech-Enabled Business Trends to Watch. McKinsey Quarterly, 4, 26-43.

6. Carroll, A. B. and Buchholtz, A. K. 2009. Business and Society: Ethics and Stakeholder Management. 7th Edition. South-Western.

7. Chan, C. A. and Pearson, C. A. L. 2002. Comparison of Managerial Work Goals among Bruneian, Malaysian and Singaporean Managers. The Journal of Management Development, 21, 545-556.

8. Clark, M. M. 2005. Employees, HR Differ on Satisfaction Factors. HR Magazine, August, 32, 40.

9. Corney, W. J. and Richards, C. H. 2001. Work Goal Differences: Post Communist versus Capitalist Economies. International Journal of Management, 18, 294-300.

10. Corney, W. J. and Richards, C. H. 2005. A Comparative Analysis of the Desirability of Work Characteristics: Chile versus the United States. International Journal of Management, 22, 159-165.

11. Dawis, R. V. and Lofquist, L. H. 1984. A Psychological Theory of Work Adjustment: An Individual Differences Model and Its Applications. Minneapolis: University of Minnesota Press.

12. Dodd, N. G. and Ganster, D. C. 1996. The Interactive Effects of Autonomy, Variety, and Feedback on Attitudes and Performance. Journal of Occupational Behavior, 17, 329-347.

13. Edwards, J. R. 1991. Person-Job Fit: A Conceptual Integration, Literature Review, and Methodological Critique. International Review of Industrial and Organizational Psychology, 6, 283-357. 
14. Ejere, E. (2010). The Importance of Work Goals among a Selected Group of Senior Public Servants in Nigeria. Interdisciplinary Journal of Contemporary Research in Business, 1(11), 191-201.

15. Hammer, M. and Champy, J. 1993. Reengineering the Corporation. New York: Harper Business.

16. Harpaz, I. 1990. The Importance of Work Goals: An International Perspective. Journal of International Business Studies, 21, 75-93.

17. Harpaz, I. and Xuanning, F. 2002. The Structure of the Meaning of Work: A Relative Stability amidst Change. Human Relations, 55, 639-667.

18. Harris, C., Daniels, K. and Briner, R. B. 2003. A Daily Diary Study of Goals and Affective Well-Being at Work. Journal of Occupational and Organizational Psychology, 76, 401-410.

19. Hershenson, D. B. 1996. Work Adjustment: A Neglected Area in Career Counseling. Journal of Counseling and Development, 74, 442-449.

20. Klein, K. J., Knight, A. P., Ziegert, J. C., Lim, B. C., and Saltz, J. L. 2011. When Team Members' Values Differ: The Moderating Role of Team Leadership. Organizational Behavior and Human Decision Processes, $114,25-36$.

21. Kulik, C. T., Oldham, G. R., and Hackman, J. R. 1987. Work Design as an Approach to Person-Environment Fit. Journal of Vocational Behavior, 31, 278-296.

22. Locke, E. A. 1976. The Nature and Causes of Job Satisfaction. In M.D. Dunnette (Ed.), Handbook of Industrial and Organizational Psychology, 1297-1349. Chicago: Rand McNally.

23. Maier, G. W. and Brunstein, J. C. 2001. The Role of Personal Work Goals in Newcomers' Job Satisfaction and Organizational Commitment: A Longitudinal Analysis. Journal of Applied Psychology, 86, 1034-1042.

24. MOW International Research Team. 1987. The Meaning of Work. London: Academic Press.

25. Pearson, C. A. L. and Chatterjee, J. R. 1999. Changing Work Values of Senior Indian Managers: An Empirical Study. International Journal of Management, 16, 139-146.

26. Peterson, M. F. and Ruiz-Quintanilla, S. A. 2003. Cultural Socialization as a Source of Intrinsic Work Motivation. Group and Organization Management, 28, 188-216.

27. Rich, B. L., LePine, J. and Crawford, E. R. 2010. Job Engagement: Antecedents and Effects on Job Performance. Academy of Management Journal, 53, 3, 617-635.

28. Richards, C. H. and Corney, W. J. 2008. Business Student and Practitioner Work Goals and Their Implications. Journal of Business and Economics Research, 6, 39-46.

29. Roberson, L. 1990. Prediction of Job Satisfaction from Characteristics of Personal Work Goals. Journal of Organizational Behavior, 11, 29-41.

30. Stewart, G. L., Manz, C. C., and Sims, H. P. 1999. Team Work and Group Dynamics. New York: John Wiley and Sons.

31. Trist, E. L. 1981. The Evolution of Socio-Technical Systems. Toronto: Quality of Working Life Center.

32. Weiner, Y. and Klein, K.L. 1978. The Relationship between Vocational Interests and Job Satisfaction: Reconciliation of Divergent Results. Journal of Vocational Behavior, 13, 298-304. 